Document downloaded from:

http://hdl.handle.net/10251/141457

This paper must be cited as:

Quiles-Carrillo, L.; Montanes, N.; Garcia-Garcia, D.; Carbonell-Verdu, A.; Balart, R.; TorresGiner, S. (2018). Effect of different compatibilizers on injection-molded green composite pieces based on polylactide filled with almond shell flour. Composites Part B Engineering. 147:76-85. https://doi.org/10.1016/j.compositesb.2018.04.017

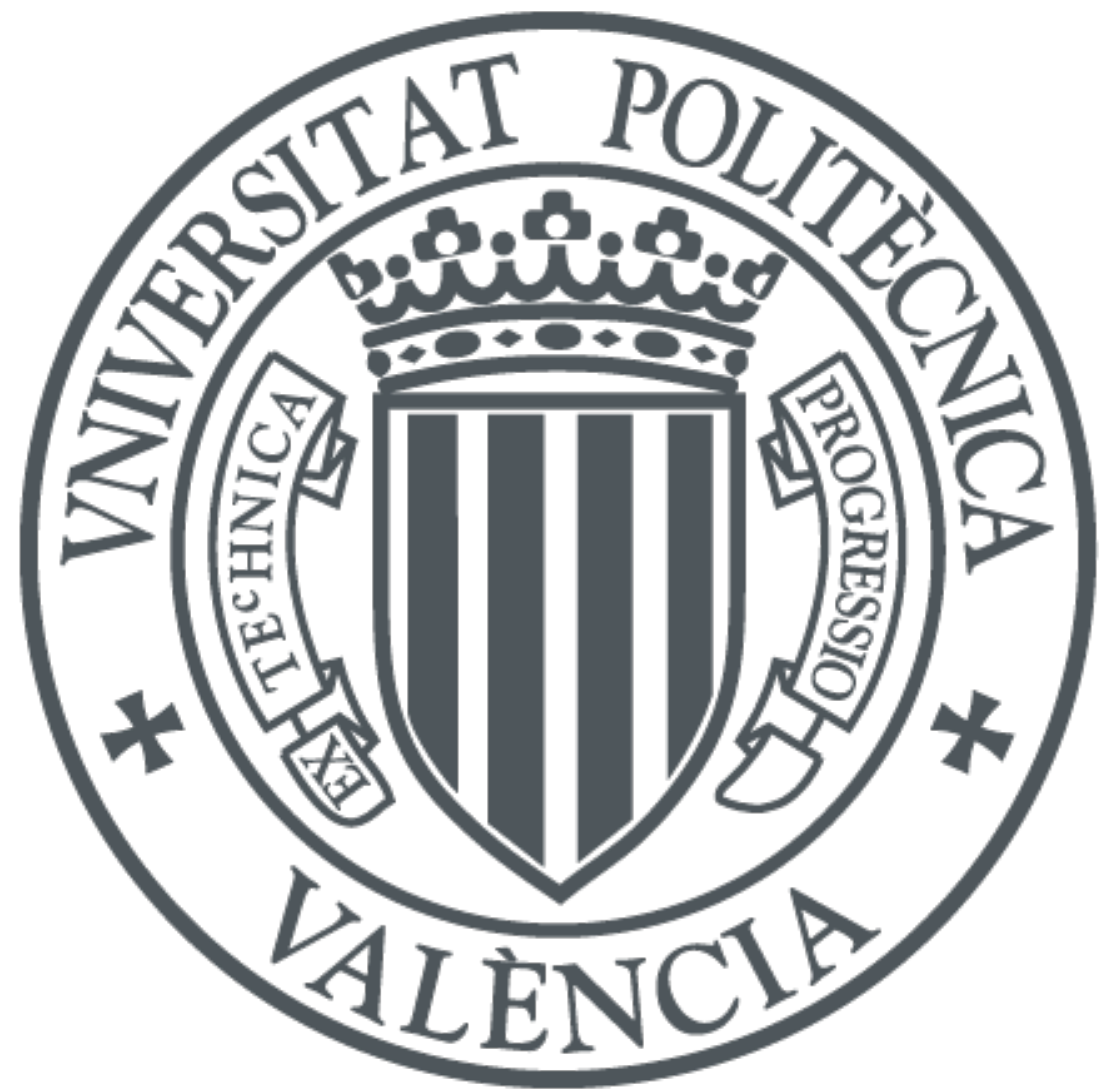

The final publication is available at

https://doi.org/10.1016/j.compositesb.2018.04.017

Copyright Elsevier

Additional Information 


\title{
Effect of different compatibilizers on injection-molded green composite pieces based on polylactide filled with almond shell flour
}

\author{
L. Quiles-Carrillo a, N. Montanes ${ }^{\text {a }}$, D. Garcia-Garcia ${ }^{\text {a }}$, A. Carbonell-Verdu ${ }^{\text {a }}$, R. Balart ${ }^{\text {a }}$ and S. Torres- \\ Giner $^{\mathrm{a}, \mathrm{b}^{*}}$ \\ [a] Technological Institute of Materials (ITM), Universitat Politècnica de València (UPV), Plaza Ferrándiz y \\ Carbonell 1, 03801 Alcoy, Spain \\ [b] Novel Materials and Nanotechnology Group, Institute of Agrochemistry and Food Technology (IATA), Spanish \\ Council for Scientific Research (CSIC), Calle Catedrático Agustín Escardino Benlloch 7, 46980 Paterna, Spain \\ *Corresponding author: S. Torres-Giner (storresginer@iata.csic.es and storresginer@upv.es)
}

\begin{abstract}
Green composites made of polylactide (PLA) filled with almond shell flour (ASF) at a constant weight content of $25 \mathrm{wt} .-\%$ were manufactured by injection molding. In order to increase the interfacial adhesion between the biopolymer and the lignocellulosic fillers, three different compatibilizers were tested, namely multi-functional epoxy-based styrene-acrylic oligomer (ESAO), aromatic carbodiimide (AC), and maleinized linseed oil (MLO). The effect of each compatibilizer on the thermal, mechanical, and thermomechanical properties and water uptake of the injection-molded PLA/ASF pieces was analyzed. The obtained results indicated that all the here-studied compatibilizers had a positive influence on both the thermal stability and the mechanical and thermomechanical performance of the green composite pieces but low impact on their water uptake profile. In addition, the morphological analysis performed at the fracture surfaces of the green composite pieces revealed that the filler-matrix gap was substantially reduced. Among the tested compatibilizers, ESAO and MLO yielded the highest performance in terms of mechanical strength and ductility, respectively. In the case of MLO, it also offers the advantage of being a plant-derived additive so that its application in green composites positively contributes to the development of sustainable polymer technologies.
\end{abstract}

Keywords: PLA; Multi-functional epoxy-based styrene-acrylic oligomer; Aromatic carbodiimide; Maleinized linseed oil; Agro-food waste. 


\section{Introduction}

Nowadays, the increasing concern about environmental issues derived from the use of nonrecyclable and petroleum-derived materials is promoting the development of environmentally friendly high-performance polymer materials [1]. Green composites represent an interesting sustainable solution as they are typically made of a biopolymer matrix and a plant-derived filler $[2,3]$. These materials are being increasingly applied in a wide variety of sectors such as automotive, building and construction, packaging, etc. [4-8]. Furthermore, the use of green composites is gaining an increasing interest in the Circular Economy since these materials are not only obtained from natural resources but they can also be fully disintegrated under controlled compost conditions [9]. In the emerging bioplastics market, polylactide (PLA) is currently considered the front runner due to its good balance between physical properties and its two-fold environmental advantage of being a bio-based and biodegradable material [10].

From an environmental point of view, lignocellulosic materials obtained from industrial byproducts and food or agroforestry waste are also gaining certain relevance as cost-effective fillers due to their positive dual contribution on natural origin and biodegradability, i.e. disintegration in compost soil $[11,12]$. In recent years, it has been reported the use of a wide variety of these plantderived fillers such as rice hull [13-15], peanut skin [16, 17], Posidonia oceanica seagrass [18], corn cob and sunflower hull [19], pineapple flour [20], etc. In this context, almond shell flour (ASF) particles are very promising fillers in green composites due to the increasing consumption of pastries, almond milk, and other almond-derived products in the food industry [21, 22]. In particular, the worldwide annual production of almond (Prunus amygdalus L.) is 2.31 million tons from a land area of 1.7 million hectare [23], being Spain the second biggest producer with approximately 0.3 million tons. Since the almond by-products, i.e. hulls and shells, account for more than $50 \%$ by dry weight of the almond fruit [24], it is estimated that around $0.8-1.7$ million tons of them are annually wasted [25]. Therefore, the use of this agro-food waste currently represents a smart solution to generate high-added value materials in the plastic industry [26, 27]. 
Unfortunately, there are some drawbacks related to the incorporation of lignocellulosic fillers into polymers, which are mainly related to their poor filler-matrix interfacial adhesion and the potential formation of particle aggregates. In general, polymers, including biopolyesters, are highly hydrophobic or low hydrophilic whereas the lignocellulosic fillers are extremely hydrophilic [28]. Such low chemical affinity is certainly responsible for their lack of compatibility, thus leading to green composite materials with poor overall physical properties [29-31]. In most cases, this particularly induces an impairment on the mechanical ductility and thermal stability of the resultant green composites [32].

The use of compatibilizers currently represents a straightforward strategy to enhance the interfacial adhesion between the lignocellulosic fillers and a wide range of polymer matrices [16, 33, 34]. Reactive compatibilizers are specifically designed to form chemical bridges during the melt processing between the two distinct phases that constitute the polymer composites, the socalled reactive extrusion (REX) [35]. Compatibilization is achieved by the melt grafting of the fillers onto the biopolymer through the use of chemical structures with at least two average functionalities $(f)$ [36]. Indeed, most commercially available reactive compatibilizers consist of polymers with low molecular weight $\left(\mathrm{M}_{\mathrm{W}}\right)$ or oligomers in which a certain numbers of functional groups (e.g. epoxy and maleic anhydride groups) are prone to react during melt processing [37]. If the main polar polymer chains that constitute the matrix of the polymer composite are characterized by terminal hydroxyl and carboxylic acid groups, these can then establish chemical reactions with some functional groups of the compatibilizer. In addition, due to the compatibilizer presents $f \geq 2$, other functional groups can also react with the hydroxyl groups exposed on the surface of the lignocellulosic filler. In this sense, both epoxy and maleic anhydride groups have been reported to efficiently react with the hydroxyl groups of both the PLA chains and cellulose on the fillers surface $[38,39]$. Moreover, as these additives can additionally offer a chainextension effect, these can positively reduce hydrolytic degradation during manufacturing and then improve melt stability [40-43]. 
This work originally reports on the effect of three reactive compatibilizers based on different chemical functionalities, namely epoxy, carbodiimide, and maleic anhydride on PLA/ASF composite pieces obtained by injection molding. To this end, the thermal, mechanical, thermomechanical properties as well as morphology and water uptake of the injection-molded green composite pieces were characterized and related to the type of compatibilizer employed.

\section{Experimental}

\subsection{Materials}

Aliphatic polyester PLA was Ingeo ${ }^{\mathrm{TM}}$ biopolymer 6201D, obtained from NatureWorks (Minnetonka, MN, USA). This is a PLA grade with a density of $1.24 \mathrm{~g} \cdot \mathrm{cm}^{-3}$ and a met flow rate (MFR) of $15-30 \mathrm{~g} / 10 \mathrm{~min}\left(210{ }^{\circ} \mathrm{C}\right.$ and $\left.2.16 \mathrm{~kg}\right)$, which makes it suitable for injection molding. Almond was collected in the Sierra Mariola region and the shells were provided by Jesol Materias Primas S.A. (Valencia, Spain) as an industrial by-product after seed extraction. Multi-functional epoxy-based styrene-acrylic oligomer (ESAO), aromatic carbodiimide (AC), and maleinized linseed oil (MLO) were used as the compatibilizers. Table 1 summarizes their commercial information, chemical structures, and relevant properties provided by the manufacturers.

\subsection{Preparation of green composites}

Prior to processing, ASF was prepared as described in previous research [39]. Briefly, the asreceived almond shells were ground in an SK 100 Cross Beater mill from Retsch GmbH (Düsseldorf, Germany) at a rotating speed of 10,000 rpm. The resultant flour was then processed in a RP09 CISA $^{\circledR}$ (Barcelona, Spain) sieve shaker to obtain a flour with a homogenous particle size distribution with a top-cut of $150 \mu \mathrm{m}$.

All materials were dried in a dehumidifier MDEO from Industrial Marsé (Barcelona, Spain) at a temperature of $60^{\circ} \mathrm{C}$ for $36 \mathrm{~h}$. ESAO was not dried due to its low glass transition temperature $\left(\mathrm{T}_{\mathrm{g}}\right.$ $=54^{\circ} \mathrm{C}$ ). A fixed weight content of 25 wt. $\%$ of ASF in PLA was set while each compatibilizer 
was added at 1 part per hundred resin (phr) of composite. A neat PLA sample and a PLA/ASF sample without any compatibilizer were produced in same conditions as the control materials.

Materials were melt compounded in a co-rotating twin-screw extruder from Construcciones Mecanicas Dupra, S.L. (Alicante, Spain). The screws feature $25 \mathrm{~mm}$ diameter with a length-todiameter ratio, i.e. $\mathrm{L} / \mathrm{D}$, of 24 . All materials were fed through the main hopper. The temperature profile was set as follows: $180^{\circ} \mathrm{C}$ (feeding zone), $185^{\circ} \mathrm{C}, 190{ }^{\circ} \mathrm{C}$, and $195^{\circ} \mathrm{C}$ (die). A rotating speed of $20 \mathrm{rpm}$ was selected. Residence time was approximately $1 \mathrm{~min}$. The extruded materials were finally pelletized using an air-knife unit.

The resultant green composite pellets were shaped into pieces by injection molding in a Meteor 270/75 from Mateu \& Solé (Barcelona, Spain). The temperature profile was set as follows: 170 ${ }^{\circ} \mathrm{C}$ (hopper), $175^{\circ} \mathrm{C}, 180{ }^{\circ} \mathrm{C}$, and $185^{\circ} \mathrm{C}$ (injection nozzle). A clamping force of 75 tons was applied. The cavity filling and cooling time were set at 1 and $10 \mathrm{~s}$, respectively. Pieces with a thickness of $4 \mathrm{~mm}$ were obtained.

\subsection{Scanning electron microscopy}

The morphologies of the ASF particles and the fractured surfaces of the green composite samples after the impact test were observed by field emission scanning electron microscopy (FESEM). This was performed in a ZEISS ULTRA 55 from Oxford Instruments (Abingdon, United Kingdom). Samples surfaces were coated, prior to analysis, with a gold-palladium alloy in a Quorum Technologies Ltd EMITECH model SC7620 sputter coater (East Sussex, UK). An acceleration voltage of $2 \mathrm{kV}$ was applied. Sizes were determined using Image J Launcher v 1.41 and the data presented were based on measurements from a minimum of 50 SEM micrographs.

\subsection{Color measurements}

A Konica CM-3600d Colorflex-DIFF2, from Hunter Associates Laboratory, Inc. (Reston, Virginia, USA) was used for the color measurement. Color indexes $\left(\mathrm{L}^{*}, \mathrm{a}^{*}\right.$, and $\left.\mathrm{b}^{*}\right)$ were measured according to following criteria: $\mathrm{L}^{*}=0$, darkness; $\mathrm{L}^{*}=100$, lightness; $+\mathrm{a}^{*}=$ red, $-\mathrm{a}^{*}=$ green; and $+\mathrm{b}^{*}=$ yellow, $-\mathrm{b}^{*}=$ blue. Measurements were done in triplicate. 


\subsection{Thermal characterization}

Main thermal transitions of green composite pieces were obtained by differential scanning calorimetry (DSC) in a Mettler-Toledo 821 calorimeter (Schwerzenbach, Switzerland). An average sample weight ranging from 5 to $7 \mathrm{mg}$ was subjected to a thermal cycle as follows: First heating from $30{ }^{\circ} \mathrm{C}$ to $200{ }^{\circ} \mathrm{C}$, cooling down to $0{ }^{\circ} \mathrm{C}$, and second heating to $350{ }^{\circ} \mathrm{C}$. Heating and cooling rates were set at $10{ }^{\circ} \mathrm{C} \cdot \mathrm{min}^{-1}$. All tests were run in nitrogen atmosphere $\left(66 \mathrm{~mL} \mathrm{~min}^{-1}\right)$ with standard sealed aluminium crucibles of a volume capacity of $40 \mu \mathrm{L}$. The degree of crystallinity $\left(X_{c}\right)$ was calculated by using the following expression (Eq. 1):

$$
X_{C}=\left[\frac{\Delta H_{m}-\Delta \boldsymbol{H}_{C C}}{\Delta H_{m}^{0} \cdot(1-w)}\right] \cdot 100 \quad \text { Equation 1 }
$$

Where $\Delta \boldsymbol{H}_{\boldsymbol{m}}$ and $\Delta \boldsymbol{H}_{\boldsymbol{C}}\left(\mathrm{J} \cdot \mathrm{g}^{-1}\right)$ stand for the melt and cold crystallization enthalpies, respectively, $\left(\Delta \boldsymbol{H}_{\boldsymbol{m}}^{\mathbf{0}}\right)\left(\mathrm{J} \cdot \mathrm{g}^{-1}\right)$ represents the theoretical melt enthalpy of a fully crystalline PLA, i.e. $93.0 \mathrm{~J} \cdot \mathrm{g}^{-1}$ [44], and 1-w corresponds to the weight fraction of PLA in the sample.

Thermal stability (degradation/decomposition) was determined by thermogravimetric analysis (TGA) in a Mettler-Toledo TGA/SDTA 851 thermobalance. Samples with an average weight comprised between 5 and $7 \mathrm{mg}$ were placed in standard alumina crucibles of $70 \mu \mathrm{L}$ and subjected to a heating program from $30{ }^{\circ} \mathrm{C}$ to $700^{\circ} \mathrm{C}$ at a heating rate of $20^{\circ} \mathrm{C} \cdot \mathrm{min}^{-1}$ in air atmosphere.

\subsection{Mechanical characterization}

Tensile and flexural tests were carried out in a mechanical universal testing machine ELIB 50 from S.A.E. Ibertest (Madrid, Spain) as recommended by ISO 527 and ISO 178, respectively. This was equipped with a $5-\mathrm{kN}$ load cell. A cross-head speed was set to $5 \mathrm{~mm} \cdot \mathrm{min}^{-1}$ in both tests. Hardness was measured using the Shore D scale in a durometer model 676-D from J. Bot Instruments (Barcelona, Spain) as recommended by ISO 868. Impact strength was obtained in a 6-J Charpy pendulum from Metrotec (San Sebastián, Spain) following ISO 179. All mechanical tests were performed at room temperature testing at least six different specimens per sample. 


\subsection{Thermomechanical characterization}

The thermomechanical properties of the green composite pieces were studied by measuring the Vicat softening temperature (VST) and the heat deflection temperature (HDT) in a Vicat/HDT station VHDT 20 from Metrotec S.A. (San Sebastián, Spain). VST values were obtained according ISO 306 by the B50 method. The applied force was $50 \mathrm{~N}$ and the heating rate was 50 ${ }^{\circ} \mathrm{C} \cdot \mathrm{h}^{-1}$. HDT measurements were carried out according to ISO 75 with a distance between supporting edges of $60 \mathrm{~mm}$ and an applied weight of $320 \mathrm{~g}$. Samples sizing 4 x 10 x $80 \mathrm{~mm}^{3}$ were heated at $120^{\circ} \mathrm{C} \cdot \mathrm{h}^{-1}$. Tests were performed in triplicate.

Dynamical mechanical thermal analysis (DMTA) was conducted in an oscillatory rheometer ARG2 from TA Instruments (New Castle, USA) equipped with a special clamps system for solid samples working in torsion-shear mode. Samples with dimensions of $4 \times 10 \times 40 \mathrm{~mm}^{3}$ were subjected to a temperature sweep program from $40{ }^{\circ} \mathrm{C}$ to $100^{\circ} \mathrm{C}$ at a heating rate of $2{ }^{\circ} \mathrm{C} \cdot \mathrm{min}^{-1}$, a frequency of $1 \mathrm{~Hz}$, and a maximum shear deformation $(\gamma)$ of $0.1 \%$.

\subsection{Water uptake characterization}

Injection-molded samples of $4 \times 10 \times 80 \mathrm{~mm}^{3}$ were immersed in distilled water at $23 \pm 1^{\circ} \mathrm{C}$. The samples were taken out and weighed weekly using an analytical balance with a precision of \pm 0.1 $\mathrm{mg}$, after removing the residual water with a dry cloth. The evolution of the water absorption was followed for a period of 15 weeks. Measurements were performed in triplicate.

\section{Results and discussion}

\subsection{Fillers morphology}

The morphology of the ASF particles is shown in the FESEM images of Figure 1. As it can be observed in Figure 1a, the fillers presented an irregular shape with a great variety of diameters. The particle size was approximately $75 \mu \mathrm{m}$, as it can be seen in the histogram of the ASF powder. Further magnification of the particles, shown in Figure 1b, revealed the presence of some voids 
and granular features in their surface, which resemble the original porous-like structure of almond shell. The ASF particles also showed a rough surface, which can be a consequence of the crushing process due to the high hardness of the almond shell. A similar morphology for ASF particles has been reported in previous studies of polymer composites [26, 39, 45].

\subsection{Appearance of green composite pieces}

Figure 2 shows the appearance of the resultant injection-molded green composite pieces. It can be seen that the incorporation of ASF into PLA resulted in pieces with a dark brown color, which corresponds to the natural color of almond shell. In general, all green composites presented similar color characteristics with different intensities depending on the compatibilizer used. Table 2 summarizes the color indexes $\left(\mathrm{L}^{*} \mathrm{a} \mathrm{b}^{*}\right)$ of the injection-molded pieces. The piece with the darkest color, i.e. the sample with the lowest lightness, corresponded to the uncompatibilized green composite. This presented a $\mathrm{L}$ value of 26.4 , while the $\mathrm{a}^{*}$ and $\mathrm{b}^{*}$ color coordinates were 3.5 and 3.6, respectively. Indeed, all injection-molded pieces showed positive values for the $\mathrm{a}^{*}$ and $\mathrm{b}^{*}$ color coordinates, confirming that the incorporation of ASF produced a reddish- or brownish-like color. The three compatibilizers generated pieces with a lighter brown color, showing $\mathrm{L}$ values in the 28-32 range, being the lightest coloration observed for the MLO-treated piece. Therefore, the ASF incorporation delivered a wood-like color and surface finish, which can be interesting from an aesthetical perspective in packaging materials such as food trays for fruits and vegetables.

\subsection{Thermal properties of green composite pieces}

Figure 3 shows the DSC curves corresponding to the second heating run of the injection-molded pieces of neat PLA and its green composites processed with the different compatibilizers. Their main thermal parameters are included in Table $\mathbf{3}$.

In relation to the neat PLA piece, the initial change in slope located between $55^{\circ} \mathrm{C}$ and $65{ }^{\circ} \mathrm{C}$ is associated to its glass transition temperature $\left(\mathrm{T}_{\mathrm{g}}\right)$. The exothermic peak in the $105-130{ }^{\circ} \mathrm{C}$ range corresponds to the cold crystallization process, showing a crystallization temperature $\left(\mathrm{T}_{\mathrm{cc}}\right)$ of $112.5^{\circ} \mathrm{C}$. Cold crystallization is typically observed in PLA-based articles, which is produced due 
to an internal rearrangement of the quenched-in amorphous domains from cooling into ordered/packed (crystalline) regions when chain mobility increases above $T_{g}$ [46]. During this process, imperfect crystals of PLA are formed from unmelted ones acting as nuclei. The ASF incorporation into PLA slightly reduced the cold crystallization temperature, i.e. $\mathrm{T}_{\mathrm{cc}}$ was 111.4 ${ }^{\circ} \mathrm{C}$, which can be related to a nucleation ability of the fillers [46]. The addition of different compatibilizers generated more intense effects on the cold crystallization process. Whereas the green composite pieces compatibilized with ESAO and AC presented the cold crystallization process at higher temperatures, $\mathrm{T}_{\mathrm{cc}}$ of $c a .125$ and $120^{\circ} \mathrm{C}$, respectively, MLO induced the opposite effect and $\mathrm{T}_{\mathrm{cc}}$ moved towards lower temperatures, i.e. $103.9{ }^{\circ} \mathrm{C}$. This can be related to the significant plasticizing effect that MLO, similar to other multi-functionalized vegetable oils, can provide to the PLA matrix [10, 39, 47].

With regard to the melting temperature $\left(\mathrm{T}_{\mathrm{m}}\right)$, it can be observed that the presence of ASF also reduced $\mathrm{T}_{\mathrm{m}}$ by approximately $3{ }^{\circ} \mathrm{C}$. It is then expected that the presence of ASF slightly disrupted the folding process of the PLA chains, avoiding the formation of more perfect crystals. A similar value of $\mathrm{T}_{\mathrm{m}}$ was observed for the green composite piece compatibilized with ESAO. However, interestingly, the addition of AC and MLO maintained the original $\mathrm{T}_{\mathrm{m}}$ of PLA, i.e. approximately $172{ }^{\circ} \mathrm{C}$, which indicates that both compatibilizers did not interfere with the lamellae growth of the spherulites. For the case of AC, however, melting took place in two peaks. This can be related a process of crystal reorganization upon melting, by which less perfect crystals can order into spherulites with thicker lamellar thicknesses than thereafter melt at higher temperatures. In relation to the degree of crystallinity $\left(\mathrm{X}_{\mathrm{c}}\right)$, it can be observed that the neat PLA piece and the uncompatibilized green composite piece presented a similar degree of crystallinity of approximately $9 \%$ and $12 \%$, respectively. However, the addition of ESAO and AC considerably reduced the amount of crystallinity of the green composite pieces down to values of $3.3 \%$ and $0.9 \%$, respectively. Therefore, ESAO and AC seem to restrict crystallization in PLA, which can be caused by intermolecular chain-extension reactions that would contribute to avoid the formation of more packed and ordered regions [48]. Interestingly, MLO provided the opposite effect in comparison to the two other compatibilizers. In particular, $\mathrm{X}_{\mathrm{c}}$ increased up to values of 
$30.5 \%$ in the MLO-treated green composite piece. Similar findings have been recently reported by Balart et al. [38] for PLA/hazelnut shell flour (HSF) composites compatibilized with epoxidized linseed oil (ELO). This increase was related to the plasticizing effect of the vegetable oil, which both enhanced chain mobility and lowered polymer-polymer interactions. As a result, the PLA chains in the green composites compatibilized with MLO were more prone to order.

TGA curves of the ASF powder as well as of the neat PLA and the PLA/ASF composite pieces treated with the different compatibilizers are gathered in Figure 4. Regarding the ASF powder, its degradation was similar to that observed for other lignocellulosic materials [49, 50]. First weight loss is related to residual water removal, produced at $80-150{ }^{\circ} \mathrm{C}$. The second degradation step was observed in the $220-300{ }^{\circ} \mathrm{C}$ range, which was the highest weight loss, and it corresponds to the hemicelluloses and cellulose degradation. Although lignin starts degradation around 250 ${ }^{\circ} \mathrm{C}$, it degrades more slowly, contributing for the progressive weight loss up to $500{ }^{\circ} \mathrm{C}$. Early stages of lignin degradation overlap with cellulose and hemicellulose degradation [51]. In relation to the thermal degradation profile of injection-molded pieces, one can observe that PLA decomposed in a single step, starting approximately at $320^{\circ} \mathrm{C}$ and with a degradation temperature $\left(\mathrm{T}_{\mathrm{deg}}\right)$ located at $370{ }^{\circ} \mathrm{C}$. Degradation of the uncompatibilized PLA/ASF composite piece differed from that of the neat PLA and it proceeded in two steps. First weight loss initiated at $300{ }^{\circ} \mathrm{C}$, which indicates that the ASF incorporation reduced the thermal stability of PLA by around $30{ }^{\circ} \mathrm{C}$. This may involve the initial degradation of low- $\mathrm{M}_{\mathrm{W}}$ components of almond shell such as hemicellulose. Second weight loss was less pronounced. It appeared in the $370-490{ }^{\circ} \mathrm{C}$ range, which corresponds to the thermal degradation of both PLA and cellulose. This slope change, observed between 400 and $420{ }^{\circ} \mathrm{C}$, can be attributed to the above-indicated degradation of the lignin present in ASF.

As it can be seen in Table 4, the addition of all compatibilizers induced a positive effect on the thermal stability of the green composites. Thermal degradation values were delayed up to $10{ }^{\circ} \mathrm{C}$ in comparison to the unmodified green composite, being the highest improvement observed for the ESAO-compatibilized piece. This enhancement in the thermal stability suggests certain 
chemical interaction of the compatibilizers with both components of the composite, by which the resultant linked fillers are expected to act as a physical barrier that obstructs the removal of volatile products produced during decomposition.

\subsection{Mechanical properties of green composite pieces}

Figure 5 shows the effect of the different compatibilizers on both the tensile and flexural properties. With regard to the tensile properties, the incorporation of ASF into PLA produced an increase of the elastic modulus values. While the neat PLA piece presented a tensile modulus of $1.96 \mathrm{GPa}$, the green composite piece showed a value $2.54 \mathrm{GPa}$. However, the injection-molded piece also became more brittle since the elongation at break was reduced from $5.2 \%$, for the neat PLA piece, to $2.1 \%$, for the uncompatibilized green composite piece. This can be related to the absence (or very poor) interaction of ASF with the PLA matrix. As a matter of fact, the tensile strength varied from $63.3 \mathrm{MPa}$, for the neat PLA piece, down to $39.7 \mathrm{MPa}$, for the uncompatibilized green composite piece. It is considered that the lignocellulosic filler acted as a stress concentrator, being responsible for lowering the elongation at break and the tensile strength. Since the elastic modulus relates both the tensile strength and elongation at break, and the reduction of the latter property was much more pronounced, this supports the increase observed in the modulus after the ASF incorporation into the PLA pieces.

Interestingly, the addition of all three compatibilizers provided a positive effect on the green composite pieces in terms of tensile strength and, particularly, elongation at break. The highest improvement in the tensile strength was observed for the green composite pieces compatibilized with ESAO and AC. In particular, the values of tensile strength increased in the ESAO- and ACtreated green composite pieces up to 52.2 $\mathrm{MPa}$ and $51.2 \mathrm{MPa}$, respectively. This is an indication of the positive effect of the compatibilizers on the material cohesion, which provided a more efficient load transfer from the dispersed ASF particles to the PLA matrix. In this regard, Awal et al. [52] reported similar effects on PLA/cellulose composites compatibilized with carbodiimide. However, although AC offered enhanced mechanical properties for the green composite, the compatibilizing effect of ESAO was still superior since the mechanical strength increase was 
accompanied by a higher improvement in ductility. In particular, the elongation at break reached values of $3.3 \%$ and $2.6 \%$ for the EASO- and AC-compatibilized green composite pieces, respectively. The latter represents an increase of approximately $55 \%$ in relation to the uncompatibilized green composite piece. This can be ascribed to the fact that the multiple epoxy groups of ESAO, in addition to react with the terminal groups of PLA, are also able to react with hydroxyl groups exposed on the fillers surface [36]. In this sense, Nagaranjan et al. have also reported, that epoxy-based chain extenders can be also interesting additives for compatibilization of cellulose and cellulose-derived materials purposes and not only for biopolymer blends [53, 54]. In relation to the compatibilizing effect of MLO on the tensile properties of the green composite pieces, this provided lower values of tensile modulus and strength than the other two compatibilizers but an extraordinary improvement in mechanical ductility. In particular, the elongation at break increased to $4.5 \%$, which represents an increase of approximately $115 \%$ in relation to the uncompatibilized green composite piece. Similar results have been recently observed for PLA/ASF composites compatibilized by different amounts of MLO [39], which was ascribed to the strong plasticization provided by this multi-functionalized vegetable oil. Since the vegetable oil molecules can readily place among the biopolymer chains, then these act as a lubricant with an enhanced influence on chain mobility [55].

The effect of the compatibilizers was further evaluated by flexural tests. The neat PLA piece presented a flexural modulus of $3.71 \mathrm{GPa}$ and a flexural strength of $104.5 \mathrm{MPa}$. The uncompatibilized PLA/ASF composite piece showed an increase in the flexural modulus up to 4.68 GPa, but a noticeable decrease in the flexural strength down to $58 \mathrm{MPa}$. This further supports the poor biopolymer-filler interfacial adhesion. A similar mechanical improvement than that described above for the tensile tests were observed for the different compatibilizers. In particular, ESAO showed the highest flexural improvement since, in comparison to the uncompatibilized green composite, it presented both the lowest reduction in the flexural modulus and the highest increase in the flexural strength. In particular, the ESAO-treated green composite piece showed a flexural strength of about 96.1 MPa, which is very close that observed for the neat PLA piece. 
The green composite pieces compatibilized with AC and MLO presented values of flexural strength of 82.4 and 73.6 $\mathrm{MPa}$, respectively. Therefore, all compatibilizers provided an improvement in the mechanical properties of the PLA/ASF pieces.

As it can be seen in Table 5, the incorporation of ASF resulted in a noticeable increase of the Shore D hardness. In particular, it increased from 78 to approximately 84 , which can be related to the reinforcing effect of a hard fillers on the biopolymer matrix. The addition of all three compatibilizers produced similar Shore D hardness values, in the range of the unmodified green composite piece. In relation to impact strength, as opposite to hardness, this was highly affected by both the introduction of ASF and the addition of the different compatibilizers. While the neat PLA piece showed an impact strength of $16.1 \mathrm{~kJ} \cdot \mathrm{m}^{-2}$, which indicates that it is inherently a brittle material, the uncompatibilized green composite piece presented a value of only $6.2 \mathrm{~kJ} \cdot \mathrm{m}^{-2}$. This can be related to high content of ASF, i.e. $25 \mathrm{wt} .-\%$, that potentially produced high tensile stresses and very low deformation levels along the piece, leading to a low impact-energy absorption. Since the ability of the green composite pieces to absorb energy was remarkably compromised, this represents a crucial drawback of the green composites for most applications from a technical standpoint. Interestingly, the three tested compatibilizers induced a positive effect on the impact strength, which were in the range of $8-11 \mathrm{~kJ} \cdot \mathrm{m}^{-2}$. The highest toughness was observed for the green composite piece compatibilized with MLO, yielding an impact-strength value of $10.1 \mathrm{~kJ} \cdot \mathrm{m}^{-}$

${ }^{2}$, which represents a percentage increase of about $63 \%$ in comparison to the uncompatibilized PLA/ASF composite piece.

\subsection{Thermomechanical properties of green composite pieces}

Table 5 also includes the VST and HDT values of the injection-molded PLA/ASF composite pieces. The neat PLA piece showed a VST of $56^{\circ} \mathrm{C}$ while this value increased to $77^{\circ} \mathrm{C}$ for the green composite piece containing 25 wt.- $\%$ ASF. The addition of the compatibilizers further induced a slight increase in VST, showing values close to $80^{\circ} \mathrm{C}$ in all cases. A similar tendency was observed in the case of the HDT values. Whereas the neat PLA piece was characterized by having a HDT value of approximately $54{ }^{\circ} \mathrm{C}$, the unmodified green composite piece presented a 
value of $64^{\circ} \mathrm{C}$. The three tested compatibilizers slightly improved HDT of the pieces to values in the $66-68{ }^{\circ} \mathrm{C}$ range, which is an additional indication of their effect on enhancing the fillerbiopolymer interfacial adhesion. Therefore, the service temperature of the PLA-based pieces was increased with the incorporation of ASF while the addition of the compatibilizers reinforced this thermomechanical enhancement.

Figure 6 represents the evolution of storage modulus and damping factor $(\tan \delta) v s$. temperature for the injection-molded pieces obtained from DMTA. Figure 6a shows the evolution of the storage modulus for the neat PLA and its green composite pieces. In the case of the neat PLA piece, this presented a storage modulus value of $1.6-1.5 \mathrm{GPa}$ up to $50^{\circ} \mathrm{C}$. Then, the storage modulus sharply decreased by three orders of magnitude in the $50-70{ }^{\circ} \mathrm{C}$ range, down to values of 2-3 MPa. This phenomenon corresponds to the alpha ( $\alpha$ )-relaxation of the biopolymer, which is ascribed to the glass-rubber transition behavior and relates to the biopolymer's $\mathrm{T}_{\mathrm{g}}$. A second important change was observed in the $80-100{ }^{\circ} \mathrm{C}$ range, which is attributed to the cold crystallization process. As previously discussed during the DSC analysis, once the $\mathrm{T}_{\mathrm{cc}}$ is reached, PLA chains tend to rearrange in a more ordered structure that provides a more thermomechanical resistance. In particular, the storage modulus reached values of approximately $100 \mathrm{MPa}$. The incorporation of ASF into PLA increased the storage modulus values in the glass region to 1.91.75 GPa. Additionally, cold crystallization occurred at lower temperatures, i.e. $75-85^{\circ} \mathrm{C}$. This observation confirms that the lignocellulosic fillers acted as a nucleating agent for PLA. In addition, higher storage values, of around $250 \mathrm{MPa}$, were obtained after the cold crystallization process.

In relation to the effect of the different compatibilizers, both ESAO and AC provided a similar thermomechanical improvement. In particular, for these two compatibilizers, the storage modulus increased in the glassy region of the biopolymer up to values of $2.2-2 \mathrm{GPa}$ while the cold crystallization process was observed in a temperature range similar to that of the neat PLA piece. In the case of MLO, the piece presented lower values of storage modulus, particularly below $\mathrm{T}_{\mathrm{g}}$. Indeed, the curve of the green composite piece compatibilized with MLO was located below that 
of the uncompatibilized green composite at the whole temperature range. This confirms the plasticizing effect provided by MLO. Moreover, a decrease in the cold crystallization process was observed, as previously detected by DSC. According to these findings, the addition of MLO interestingly provided two simultaneous effects. On the one hand, MLO acted as typical plasticizer with a lubricant effect and, on the other hand, it contributed to increasing the PLAASF interfacial adhesion. These two phenomena had a positive effect on the overall polymer chain mobility, lowering both $\mathrm{T}_{\mathrm{g}}$ and $\mathrm{T}_{\mathrm{cc}}[56,57]$.

Figure $6 \mathbf{b}$ shows the evolution of $\tan \delta$ versus temperature for PLA and its green composite pieces. The peak represents the $\alpha$-relaxation of the biopolymer, which relates to its $\mathrm{T}_{\mathrm{g}}$. As it can be observed, the neat PLA piece presented a $\mathrm{T}_{\mathrm{g}}$ value of about $63^{\circ} \mathrm{C}$ and this value was slightly reduced to the $61-62{ }^{\circ} \mathrm{C}$ range for all PLA/ASF composite pieces, with the exception of the MLOtreated piece in which $T_{g}$ was even lower due to its above-described plasticizing effect on PLA. Therefore, MLO provided increased mobility and free volume, which reduced the polymer chain interactions with a direct effect on lowering the $\mathrm{T}_{\mathrm{g}}$ [58]. Another important behavior to note is the relatively low damping factor observed for the green composite pieces. Whereas the neat PLA piece showed a maximum damping factor of approximately 3.2, this decreased down to values in the 1.5-2 range in the green composite pieces. This reduction implies a lower energy dissipation and reduced toughness due to the presence of the lignocellulosic filler [28]. In particular, the PLA/ASF composite piece with the lowest damping factor, i.e. 1.6, corresponded to the ESAOcompatibilized piece.

\subsection{Morphology of green composite pieces}

Figure 7 gathers the FESEM images of the fracture surfaces of the green composite pieces, obtained after the impact tests. The fracture surface of the unmodified green composite, shown in Figure 7a, revealed the absence of ASF particles. Indeed, the uncompatibilized green composite presented several voids that would correspond to the detached particles after impact, which also copied the granular surface of the ASF particles. It is expected that, as the lignocellulosic fillers did not interact with the PLA matrix, these subsequently acted as stress concentrators. This 
supports the above-described mechanical results, indicating that the uncompatibilized green composite pieces presented a brittle behavior. Figure $\mathbf{7 b}$ shows the FESEM micrograph corresponding to the green composite piece compatibilized with ESAO. Although some voids can be yet observed after fracture, some ASF particles were attained to the PLA matrix. Interestingly, the embedded ASF particles also broke during fracture, which is an indication of their higher interfacial adhesion with PLA. In addition, the gap between the ASF particles and the surrounding biopolymer matrix was relatively low. This gap can be still detected in some particles (see black arrows) while it was fully indiscernible in others (see white arrows). With regard to the ACcompatibilized PLA/ASF composite piece, shown in Figure 7c, it also showed the presence of ASF particles embedded in the PLA matrix. Nevertheless, in this case, a larger gap between the ASF particles and the surrounding PLA matrix was observed (see white arrows). The piece also showed some gaps due to a phenomenon of particle debonding while certain plastic deformation of the PLA matrix can be also observed by the presence of long filaments. Finally, the green composite piece compatibilized with MLO, included in Figure 7d, presented a softer fracture surface with the presence of fully embedded ASF particles. This image also supports the hypothesis that the presence of MLO in the green composites improved ASF wettability based on the plasticization of the PLA matrix [59]. The filler-matrix gaps were relatively low (see white arrows) though some few voids were also discerned. In addition, phase separation was not detectable. As a result, the addition of the three compatibilizers successfully improved the adhesion between the blended components, facilitating a better stress transfer from the filler to the biopolymer matrix.

\subsection{Water uptake of green composite pieces}

One of the most important drawbacks of green composites or any material based on hydrophilic fillers is their tendency to absorb water. Figure $\mathbf{8}$ shows the evolution of the water uptake of the injection-molded pieces for a period of 15 weeks of immersion in water. The neat PLA piece presented a relatively low water absorption for the whole tested period, with an asymptotic value of approximately $0.7 \mathrm{wt} .-\%$. This supports the intrinsic hydrophobic behavior of PLA. However, 
after the incorporation of ASF, all pieces showed a considerable increase in the values of water uptake up to $4-5$ wt.- $\%$. In the case of the unmodified green composite piece, after 15 weeks, this stabilized at a water content of approximately $4.8 \mathrm{wt} .-\%$. Therefore, the ASF fillers, due to its high number of hydroxyl groups, present a high tendency to trap moisture [60]. The incorporation of ESAO and AC compatibilizers slightly reduced the water uptake profile of the green composite pieces, indicating that the available number of hydroxyl groups exposed to water was reduced. The highest improvement was particularly observed for the ESAO-compatibilized PLA/ASF composite piece, which showed a final water content of approximately 4.2 wt.- $\%$, i.e. an improvement of around $14 \%$ vs. the uncompatibilized green composite piece. Nevertheless, the water uptake increased for the green composite piece compatibilized with MLO. Particularly, its slope during the first weeks was more pronounced, showing a more typical Fickean behavior. This can be related to the above-described plasticizing effect of MLO on the PLA matrix by which its free volume is enlarged, favoring water diffusion.

\section{Conclusions}

Injection-molded green composite pieces based on PLA and ASF at $25 \mathrm{wt} .-\%$ are herein presented as an interesting sustainable solution within the Circular Economy concept since these materials are able to upgrade agro-food wastes as well as contribute to reducing the cost of bioplastics. The resultant green composite pieces, however, presented poor physical properties due to the lack of compatibility between PLA and the ASF fillers. The addition of different compatibilizers based on three different chemical functionalities, namely epoxy, carbodiimide, and maleic anhydride, was tested. All three compatibilizers successfully improved the thermal stability, mechanical performance, and thermomechanical properties of the green composite pieces though their effect on water uptake was relatively low. Compatibilization achieved was also supported by the analysis of the fracture surface of the green composites, which showed an enhancement of the interfacial adhesion between the ASF fillers and the PLA matrix. In particular, both ESAO and MLO compatibilizers provided the highest improvement in terms of mechanical strength and ductility, respectively. It was proposed that these compatibilizers, based on multi-functional 
epoxy and maleic anhydride groups, respectively, are able to enhance interfacial adhesion of the green composite components by a process of melt grafting of the ASF fillers onto the PLA chains (and partially hydrolyzed PLA chains). In the case of the multi-functionalized vegetable oil, it additionally provided certain plasticization of the PLA matrix. Additionally, compatibilization by MLO represents a more sustainable strategy for compatibilization of green composites due to their intrinsic eco-friendly condition. Future in-depth studies are being currently conducted to optimize the content of each compatibilizer as well as to explore the use of novel low- $\mathrm{M}_{\mathrm{w}}$ additives with different functionalities for the compatibilization of green composites and biopolymer blends.

\section{Acknowledgements}

This research was supported by the Spanish Ministry of Economy and Competitiveness (MINECO) program number MAT2014-59242-C2-1-R and AGL2015-63855-C2-1-R and Generalitat Valenciana (GV) program number GV/2014/008. A. Carbonell-Verdu wants to thank Universitat Politècnica de València (UPV) for his FPI grant. D. Garcia-Garcia wants to thank the Spanish Ministry of Education, Culture and Sports (MECD) for his FPU grant (FPU13/06011). L. Quiles-Carrillo also wants to thank GV for his FPI grant (ACIF/2016/182) and the MECD for his FPU grant (FPU15/03812).

\section{References}

[1] Quiles-Carrillo L, Montanes N, Boronat T, Balart R, Torres-Giner S. Evaluation of the engineering performance of different bio-based aliphatic homopolyamide tubes prepared by profile extrusion. Polymer Testing. 2017;61:421-9.

[2] Faruk O, Bledzki AK, Fink HP, Sain M. Biocomposites reinforced with natural fibers: 20002010. Progress in Polymer Science. 2012;37(11):1552-96.

[3] Shah DU. Developing plant fibre composites for structural applications by optimising composite parameters: a critical review. Journal of Materials Science. 2013;48(18):6083-107. 
[4] Dicker MPM, Duckworth PF, Baker AB, Francois G, Hazzard MK, Weaver PM. Green composites: A review of material attributes and complementary applications. Composites Part aApplied Science and Manufacturing. 2014;56:280-9.

[5] Koronis G, Silva A, Fontul M. Green composites: A review of adequate materials for automotive applications. Composites Part B-Engineering. 2013;44(1):120-7.

[6] Mohanty AK, Misra M, Drzal LT. Sustainable bio-composites from renewable resources: Opportunities and challenges in the green materials world. Journal of Polymers and the Environment. 2002;10(1-2):19-26.

[7] Zini E, Scandola M. Green composites: An overview. Polymer Composites. 2011;32(12):1905-15.

[8] Masmoudi F, Bessadok A, Dammak M, Jaziri M, Ammar E. Biodegradable packaging materials conception based on starch and polylactic acid (PLA) reinforced with cellulose. Environmental Science and Pollution Research. 2016;23(20):20904-14.

[9] Torres-Giner S, Montanes N, Fombuena V, Boronat T, Sánchez-Nacher L. Preparation and characterization of compression-molded green composite sheets made of poly(3hydroxybutyrate) reinforced with long pita fibers. Advances in Polymer Technology. 2016;DOI: 10.1002/adv.21789.

[10] Quiles-Carrillo L, Duart S, Montanes N, Torres-Giner S, Balart R. Enhancement of the mechanical and thermal properties of injection-molded polylactide parts by the addition of acrylated epoxidized soybean oil. Materials \& Design. 2018;140:54-63.

[11] Laka M, Chernyavskaya S, Maskavs M. Cellulose-containing fillers for polymer composites. Mechanics of Composite Materials. 2003;39(2):183-8.

[12] Liu R, Peng Y, Cao JZ, Chen Y. Comparison on properties of lignocellulosic flour/polymer composites by using wood, cellulose, and lignin flours as fillers. Composites Science and Technology. 2014;103:1-7.

[13] Arjmandi R, Hassan A, Majeed K, Zakaria Z. Rice Husk Filled Polymer Composites. International Journal of Polymer Science. 2015;2015:501471.

[14] Ismail MR, Yassen AAM, Afify MS. Mechanical Properties of Rice Straw Fiber-Reinforced Polymer Composites. Fibers and Polymers. 2011;12(5):648-56. 
[15] Wiebeck H, Valenzuela-Diaz FR, Esper FJ, Martin-Cortes GR, Hennies WD, Costa MVV. Tire rubber powder/rice husk ash polymer compound. In: Salgado L, Ambrozio F, editors. Advanced Powder Technology Viii, Pts 1 and 22012. p. 1547-51.

[16] Garcia-Garcia D, Carbonell-Verdu A, Jorda-Vilaplana A, Balart R, Garcia-Sanoguera D. Development and characterization of green composites from bio-based polyethylene and peanut shell. Journal of Applied Polymer Science. 2016;133(37).

[17] Zaaba NF, Ismail H, Jaafar M. Effect of Peanut Shell Powder Content on the Properties of Recycled Polypropylene (RPP)/Peanut Shell Powder (PSP) Composites. Bioresources. 2013;8(4):5826-41.

[18] Ferrero B, Fombuena V, Fenollar O, Boronat T, Balart R. Development of natural fiberreinforced plastics (NFRP) based on biobased polyethylene and waste fibers from Posidonia oceanica seaweed. Polymer Composites. 2015;36(8):1378-85.

[19] Fuqua MA, Chevali VS, Ulven CA. Lignocellulosic byproducts as filler in polypropylene: Comprehensive study on the effects of compatibilization and loading. Journal of Applied Polymer Science. 2013;127(2):862-8.

[20] Kim K-W, Lee B-H, Kim H-J, Sriroth K, Dorgan JR. Thermal and mechanical properties of cassava and pineapple flours-filled PLA bio-composites. Journal of thermal analysis and calorimetry. 2012;108(3):1131-9.

[21] Valdés A, Fenollar O, Beltrán A, Balart R, Fortunati E, Kenny JM, et al. Characterization and enzymatic degradation study of poly( $\varepsilon$-caprolactone)-based biocomposites from almond agricultural by-products. Polymer Degradation and Stability. 2016;132:181-90.

[22] Valdés García A, Ramos Santonja M, Sanahuja AB, Del Carmen Garrigós Selva M. Characterization and degradation characteristics of poly(e-caprolactone)-based composites reinforced with almond skin residues. Polymer Degradation and Stability. 2014;108:269-79.

[23] Pirayesh H, Khanjanzadeh H, Salari A. Effect of using walnut/almond shells on the physical, mechanical properties and formaldehyde emission of particleboard. Composites Part B: Engineering. 2013;45(1):858-63.

[24] Fadel JG. Quantitative analyses of selected plant by-product feedstuffs, a global perspective. Animal Feed Science and Technology. 1999;79(4):255-68. 
[25] Pirayesh H, Khazaeian A. Using almond (Prunus amygdalus L.) shell as a bio-waste resource in wood based composite. Composites Part B: Engineering. 2012;43(3):1475-9.

[26] Crespo JE, Sanchez L, Parres F, López J. Mechanical and morphological characterization of PVC plastisol composites with almond husk fillers. Polymer Composites. 2007;28(1):71-7.

[27] Gordobil O, Eguees I, Llano-Ponte R, Labidi J. Physicochemical properties of PLA lignin blends. Polymer Degradation and Stability. 2014;108:330-8.

[28] Torres-Giner S, Montanes N, Fenollar O, García-Sanoguera D, Balart R. Development and optimization of renewable vinyl plastisol/wood flour composites exposed to ultraviolet radiation. Materials \& Design. 2016;108:648-58.

[29] Borah JS, Kim DS. Recent development in thermoplastic/wood composites and nanocomposites: A review. Korean Journal of Chemical Engineering. 2016:1-15.

[30] La Mantia F, Dintcheva NT, Morrealel M, Vaca-Garcia C. Green composites of organic materials and recycled post-consumer polyethylene. Polymer International. 2004;53(11):188891.

[31] Rai B, Kumar G, Tyagi VK, Diwan RK, Niyogi UK. Development and Characterization of Green Composite from Euphorbia Coagulum and Banana Fiber. Journal of Polymer Materials. 2015;32(3):305-16.

[32] Labidi S, Alqahtani N, Alejji M. Effect of Compatibilizer on Mechanical and Physical Properties of Green Composites Based on High Density Polyethylene and Date Palm Fiber. 9th International Conference on Composite Science and Technology: 2020 - Scientific and Industrial Challenges. 2013:995-7.

[33] Garcia-Garcia D, Carbonell A, Samper MD, Garcia-Sanoguera D, Balart R. Green composites based on polypropylene matrix and hydrophobized spend coffee ground (SCG) powder. Composites Part B-Engineering. 2015;78:256-65.

[34] Nyambo C, Mohanty AK, Misra M. Effect of Maleated Compatibilizer on Performance of PLA/Wheat Straw-Based Green Composites. Macromolecular Materials and Engineering. 2011;296(8):710-8.

[35] Wei L, McDonald A. A Review on Grafting of Biofibers for Biocomposites. Materials. 2016;9(4):303. 
[36] Torres-Giner S, Montanes N, Boronat T, Quiles-Carrillo L, Balart R. Melt grafting of sepiolite nanoclay onto poly (3-hydroxybutyrate-co-4-hydroxybutyrate) by reactive extrusion with multi-functional epoxy-based styrene-acrylic oligomer. European Polymer Journal. 2016;84:693-707.

[37] Muthuraj R, Misra M, Mohanty AK. Biodegradable compatibilized polymer blends for packaging applications: A literature review. Journal of Applied Polymer Science. 2017:45726.

[38] Balart J, Fombuena V, Fenollar O, Boronat T, Sánchez-Nacher L. Processing and characterization of high environmental efficiency composites based on PLA and hazelnut shell flour (HSF) with biobased plasticizers derived from epoxidized linseed oil (ELO). Composites Part B: Engineering. 2016;86:168-77.

[39] Quiles-Carrillo L, Montanes N, Sammon C, Balart R, Torres-Giner S. Compatibilization of highly sustainable polylactide/almond shell flour composites by reactive extrusion with maleinized linseed oil. Industrial Crops and Products. 2018;111:878-88.

[40] Duarte IS, Tavares AA, Lima PS, Andrade D, Carvalho LH, Canedo EL, et al. Chain extension of virgin and recycled poly(ethylene terephthalate): Effect of processing conditions and reprocessing. Polymer Degradation and Stability. 2016;124:26-34.

[41] Meng QK, Heuzey MC, Carreau PJ. Effects of a Multifunctional Polymeric Chain Extender on the Properties of Polylactide and Polylactide/Clay Nanocomposites. International Polymer Processing. 2012;27(5):505-16.

[42] Najafi N, Heuzey MC, Carreau PJ. Polylactide (PLA)-clay nanocomposites prepared by melt compounding in the presence of a chain extender. Composites Science and Technology. 2012;72(5):608-15.

[43] Zhang YC, Yuan X, Liu Q, Hrymak A. The Effect of Polymeric Chain Extenders on Physical Properties of Thermoplastic Starch and Polylactic Acid Blends. Journal of Polymers and the Environment. 2012;20(2):315-25.

[44] Torres-Giner S, Gimeno-Alcañiz JV, Ocio MJ, Lagaron JM. Optimization of electrospun polylactide-based ultrathin fibers for osteoconductive bone scaffolds. Journal of Applied Polymer Science. 2011;122(2):914-25.

[45] Crespo JE, Balart R, Sanchez L, Lopez J. Mechanical behaviour of vinyl plastisols with cellulosic fillers. Analysis of the interface between particles and matrices. International Journal of Adhesion and Adhesives. 2007;27(5):422-8. 
[46] Jandas PJ, Mohanty S, Nayak SK. Thermal properties and cold crystallization kinetics of surface-treated banana fiber (BF)-reinforced poly(lactic acid) (PLA) nanocomposites. Journal of Thermal Analysis and Calorimetry. 2013;114(3):1265-78.

[47] Quiles-Carrillo L, Blanes-Martínez MM, Montanes N, Fenollar O, Torres-Giner S, Balart R. Reactive toughening of injection-molded polylactide pieces using maleinized hemp seed oil. European Polymer Journal. 2018;98:402-10.

[48] Baimark Y, Srihanam P. Influence of chain extender on thermal properties and melt flow index of stereocomplex PLA. Polymer Testing. 2015;45:52-7.

[49] Kim S-K, Lee T. Degradation of lignocellulosic materials under sulfidogenic and methanogenic conditions. Waste Management. 2009;29(1):224-7.

[50] Morrell JJ. Degradation of Lignocellulosic Materials and Its Prevention. Jom. 2014;66(4):580-7.

[51] Tserki V, Matzinos P, Kokkou S, Panayiotou C. Novel biodegradable composites based on treated lignocellulosic waste flour as filler. Part I. Surface chemical modification and characterization of waste flour. Composites Part A: Applied Science and Manufacturing. 2005;36(7):965-74.

[52] Awal A, Rana M, Sain M. Thermorheological and mechanical properties of cellulose reinforced PLA bio-composites. Mechanics of Materials. 2015;80:87-95.

[53] Nagarajan V, Mohanty AK, Misra M. Perspective on polylactic acid (PLA) based sustainable materials for durable applications: Focus on toughness and heat resistance. ACS Sustainable Chemistry \& Engineering. 2016;4(6):2899-916.

[54] Frenz V, Scherzer D, Villalobos M, Awojulu A, Edison M, van der Meer R. Multifunctional polymers as chain extenders and compatibilizers for polycondensates and biopolymers. Society of Plastics Engineers Annual Technical Conference, Wisconsin, USA. 2008. p. 1682-7.

[55] Chieng B, Ibrahim N, Then Y, Loo Y. Epoxidized Vegetable Oils Plasticized Poly(lactic acid) Biocomposites: Mechanical, Thermal and Morphology Properties. Molecules. 2014;19(10):16024.

[56] Ferri JM, Garcia-Garcia D, Sánchez-Nacher L, Fenollar O, Balart R. The effect of maleinized linseed oil (MLO) on mechanical performance of poly(lactic acid)-thermoplastic starch (PLATPS) blends. Carbohydrate Polymers. 2016;147:60-8. 
[57] Pivsa-Art W, Fujii K, Nomura K, Aso Y, Ohara H, Yamane H. The effect of poly (ethylene glycol) as plasticizer in blends of poly (lactic acid) and poly (butylene succinate). Journal of Applied Polymer Science. 2016;133(8).

[58] Qiu ZB, Yang WT. Crystallization kinetics and morphology of poly(butylene succinate)/poly(vinyl phenol) blend. Polymer. 2006;47(18):6429-37.

[59] Ferri J, Garcia-Garcia D, Montanes N, Fenollar O, Balart R. The effect of maleinized linseed oil as biobased plasticizer in poly (lactic acid)-based formulations. Polymer International. 2017;66(6):882-91.

[60] Kuciel S, Jakubowska P, Kuzniar P. A study on the mechanical properties and the influence of water uptake and temperature on biocomposites based on polyethylene from renewable sources. Composites Part B-Engineering. 2014;64:72-7. 


\section{Figure Captions}

Figure 1. Field emission scanning electron microscopy (FESEM) images of almond shell flour (ASF) particles taken at: a) 100x with a scale marker of $100 \mu \mathrm{m}$ and the ASF powder histogram; b) $500 \mathrm{x}$ with a scale marker of $10 \mu \mathrm{m}$.

Figure 2. Surface aspect of the injection-molded pieces made of: a) Neat polylactide (PLA); b) Uncompatibilized PLA/almond shell flour (ASF); c) Compatibilized PLA/ASF with multifunctional epoxy-based styrene-acrylic oligomer (ESAO); d) Compatibilized PLA/ASF with aromatic carbodiimide (AC); e) Compatibilized PLA/ASF with maleinized linseed oil (MLO).

Figure 3. Differential scanning calorimetry (DSC) curves of the injection-molded pieces made of neat polylactide (PLA) and its green composites with almond shell flour (ASF) compatibilized with multi-functional epoxy-based styrene-acrylic oligomer (ESAO), aromatic carbodiimide (AC), and maleinized linseed oil (MLO).

Figure 4. Thermal stability of the injection-molded pieces made of neat polylactide (PLA) and its green composites with almond shell flour (ASF) compatibilized with multi-functional epoxybased styrene-acrylic oligomer (ESAO), aromatic carbodiimide (AC), and maleinized linseed oil (MLO) in terms of: a) Thermogravimetric analysis (TGA) curves; b) Derivative thermogravimetric (DTG) curves.

Figure 5. Mechanical properties of the injection-molded pieces made of neat polylactide (PLA) and its green composites with almond shell flour (ASF) compatibilized with multi-functional epoxy-based styrene-acrylic oligomer (ESAO), aromatic carbodiimide (AC), and maleinized linseed oil (MLO) in terms of: a) Tensile properties (tensile modulus and tensile strength) and elongation at break); b) Flexural properties (flexural modulus and flexural strength).

Figure 6. Dynamical mechanical thermal analysis (DMTA) curves of the injection-molded pieces made of neat polylactide (PLA) and its green composites with almond shell flour (ASF) compatibilized with multi-functional epoxy-based styrene-acrylic oligomer (ESAO), aromatic carbodiimide (AC), and maleinized linseed oil (MLO) in terms of: a) Storage modulus; b) Damping factor. 
Figure 7. Field emission scanning electron microscopy (FESEM) images of the fracture surfaces of the injection-molded pieces made of: a) Uncompatibilized polylactide (PLA)/almond shell flour (ASF); b) Compatibilized PLA/ASF with multi-functional epoxy-based styrene-acrylic oligomer (ESAO); c) Compatibilized PLA/ASF with aromatic carbodiimide (AC); d) Compatibilized PLA/ASF with maleinized linseed oil (MLO). Scale markers of $10 \mu \mathrm{m}$.

Figure 8. Water uptake of the injection-molded pieces made of neat polylactide (PLA) and its green composites with almond shell flour (ASF) compatibilized with multi-functional epoxybased styrene-acrylic oligomer (ESAO), aromatic carbodiimide (AC), and maleinized linseed oil (MLO). 
Table 1. Summary of the different compatibilizers with their main relevant information.

\begin{tabular}{|c|c|c|c|c|}
\hline Compatibilizer & $\begin{array}{c}\text { Commercial } \\
\text { code }\end{array}$ & Supplier & Chemical structure & Description \\
\hline $\begin{array}{l}\text { Multi-functional } \\
\text { epoxy-based styrene- } \\
\text { acrylic oligomer } \\
\text { (ESAO) }\end{array}$ & $\begin{array}{c}\text { Joncryl }^{\circledR} \text { ADR } \\
4368-\mathrm{C}\end{array}$ & $\begin{array}{l}\text { BASF S.A. } \\
\text { (Barcelona, Spain) }\end{array}$ & & $\begin{array}{l}\text { Molecular weight }\left(\mathrm{M}_{\mathrm{w}}\right)= \\
6800 \mathrm{~g} \cdot \mathrm{mol}^{-1} \\
\text { Glass transition } \\
\text { temperature }\left(\mathrm{T}_{\mathrm{g}}\right)=54^{\circ} \mathrm{C} \\
\text { Epoxy equivalent weight } \\
\left(\mathrm{EE}_{\mathrm{w}}\right)=285 \mathrm{~g} \cdot \mathrm{mol}^{-1}\end{array}$ \\
\hline $\begin{array}{l}\text { Aromatic } \\
\text { carbodiimide (AC) }\end{array}$ & $\begin{array}{c}\text { BioAdimide }^{\circledR} 500 \\
\text { XT }\end{array}$ & $\begin{array}{l}\text { Rhein Chemie } \\
\text { Rheinau GmbH } \\
\text { (Mannheim, } \\
\text { Germany) }\end{array}$ & & $\begin{array}{l}\text { Carbodiimide content } \\
(\mathrm{CC})>13 \%\end{array}$ \\
\hline
\end{tabular}




\begin{tabular}{|l|l|l|l|l|l|}
\hline Maleinized linseed & VEOMER LIN & Vandeputte & (Mouscron, & Belgium) &
\end{tabular}

Table 2. Color indexes $\left(\mathrm{L}^{*}, \mathrm{a}^{*}, \mathrm{~b}^{*}\right)$ of the injection-molded pieces made of neat polylactide (PLA) and its green composites with almond shell flour (ASF) compatibilized with multi-functional epoxy-based styrene-acrylic oligomer (ESAO), aromatic carbodiimide (AC), and maleinized linseed oil (MLO).

\begin{tabular}{|l|c|c|c|}
\hline \multicolumn{1}{|c|}{ Sample } & $\boldsymbol{L}^{*}$ & $\boldsymbol{a}^{*}$ & $\boldsymbol{b}^{*}$ \\
\hline PLA & $94.1 \pm 0.2$ & $-1.1 \pm 0.1$ & $1.4 \pm 0.1$ \\
\hline PLA/ASF & $26.4 \pm 0.2$ & $3.5 \pm 0.1$ & $3.6 \pm 0.2$ \\
\hline PLA/ASF + ESAO & $28.4 \pm 0.3$ & $3.4 \pm 0.2$ & $3.3 \pm 0.1$ \\
\hline PLA/ASF + AC & $29.5 \pm 0.2$ & $4.9 \pm 0.2$ & $6.5 \pm 0.2$ \\
\hline PLA/ASF + MLO & $31.9 \pm 0.1$ & $5.3 \pm 0.2$ & $6.3 \pm 0.2$ \\
\hline
\end{tabular}


Table 3. Thermal properties obtained from the differential scanning calorimetry (DSC) curves in terms of normalized enthalpy of cold crystallization ( $\left.\Delta \mathrm{H}_{\mathrm{cc}}\right)$, cold crystallization temperature $\left(\mathrm{T}_{\mathrm{cc}}\right)$, normalized enthalpy of melting $\left(\Delta \mathrm{H}_{\mathrm{m}}\right)$, melting temperature $\left(\mathrm{T}_{\mathrm{m}}\right)$, and percentage of crystallinity $\left(\mathrm{X}_{\mathrm{c}}\right)$ of the injectionmolded pieces made of neat polylactide (PLA) and its green composites with almond shell flour (ASF) compatibilized with multi-functional epoxy-based styrene-acrylic oligomer (ESAO), aromatic carbodiimide (AC), and maleinized linseed oil (MLO).

\begin{tabular}{|l|c|c|c|c|c|}
\hline Sample & $\Delta \mathbf{H}_{\mathbf{c c}}$ & $\mathbf{T}_{\mathbf{c c}}$ & $\Delta \mathbf{H}_{\mathbf{m}}$ & $\mathbf{T}_{\mathbf{m}}$ & $\mathbf{X}_{\mathbf{c}}$ \\
& $\left(\mathbf{J}^{\cdot} \mathbf{g}^{-1}\right)$ & $\left({ }^{\circ} \mathbf{C}\right)$ & $\left(\mathbf{J}^{-} \mathbf{g}^{-1}\right)$ & $\left({ }^{\circ} \mathbf{C}\right)$ & $(\boldsymbol{\%})$ \\
\hline PLA & $25.1 \pm 0.6$ & $112.5 \pm 1.1$ & $33.7 \pm 0.4$ & $172.1 \pm 1.1$ & $9.2 \pm 0.4$ \\
\hline PLA/ASF & $22.6 \pm 0.6$ & $111.4 \pm 0.9$ & $30.9 \pm 0.3$ & $169.6 \pm 0.9$ & $11.9 \pm 0.3$ \\
\hline PLA/ASF + ESAO & $22.3 \pm 0.7$ & $125.3 \pm 0.8$ & $24.6 \pm 0.3$ & $167.8 \pm 1.0$ & $3.3 \pm 0.4$ \\
\hline PLA/ASF + AC & $24.9 \pm 0.5$ & $120.0 \pm 0.9$ & $25.5 \pm 0.3$ & $171.3 \pm 0.8$ & $0.9 \pm 0.3$ \\
\hline PLA/ASF + MLO & $10.6 \pm 0.6$ & $103.9 \pm 1.0$ & $31.7 \pm 0.4$ & $172.3 \pm 0.9$ & $30.5 \pm 0.4$ \\
\hline
\end{tabular}


Table 4.- Thermal properties obtained from the thermogravimetry analysis (TGA) curves of the injection-molded pieces made of neat polylactide (PLA) and its green composites with almond shell flour (ASF) compatibilized with multi-functional epoxy-based styrene-acrylic oligomer (ESAO), aromatic carbodiimide (AC), and maleinized linseed oil (MLO). Residual mass was determined at $700{ }^{\circ} \mathrm{C}$

\begin{tabular}{|c|c|c|c|c|c|c|}
\hline \multirow[t]{2}{*}{ Sample } & \multicolumn{3}{|c|}{$1^{\text {st }}$ step } & \multicolumn{3}{|c|}{$2^{\text {nd }}$ step } \\
\hline & $\begin{array}{c}\text { Onset } \\
\left({ }^{\circ} \mathrm{C}\right)\end{array}$ & $\begin{array}{c}\text { EndSet } \\
\left({ }^{\circ} \mathrm{C}\right)\end{array}$ & Residual mass (\%) & $\begin{array}{c}\text { Onset } \\
\left({ }^{\circ} \mathbf{C}\right)\end{array}$ & $\begin{array}{c}\text { EndSet } \\
\left({ }^{\circ} \mathrm{C}\right)\end{array}$ & Residual mass (\%) \\
\hline PLA & $334.6 \pm 1.1$ & $392.6 \pm 1.0$ & $2.1 \pm 0.2$ & - & - & $0.7 \pm 0.1$ \\
\hline PLA/ASF & $315.5 \pm 1.0$ & $373.3 \pm 1.2$ & $15.0 \pm 0.3$ & $373.3 \pm 1.0$ & $486.0 \pm 0.9$ & $0.9 \pm 0.1$ \\
\hline PLA/ASF + ESAO & $317.3 \pm 0.1$ & $383.7 \pm 1.1$ & $10.2 \pm 0.2$ & $383.7 \pm 1.0$ & $490.9 \pm 1.0$ & $0.6 \pm 0.1$ \\
\hline PLA/ASF + AC & $311.0 \pm 0.9$ & $377.6 \pm 1.0$ & $14.0 \pm 0.2$ & $377.6 \pm 1.0$ & $494.8 \pm 1.1$ & $0.7 \pm 0.1$ \\
\hline PLA/ASF + MLO & $315.5 \pm 1.0$ & $378.8 \pm 1.0$ & $14.2 \pm 0.2$ & $378.8 \pm 0.5$ & $463.0 \pm 1.0$ & $0.8 \pm 0.1$ \\
\hline
\end{tabular}


Table 5.- Shore D hardness, impact strength, Vicat softening temperature (VST), and heat deflection temperature (HDT) of the injection-molded pieces made of neat polylactide (PLA) and its green composites with almond shell flour (ASF) compatibilized with multi-functional epoxy-based styrene-acrylic oligomer (ESAO), aromatic carbodiimide (AC), and maleinized linseed oil (MLO).

\begin{tabular}{|l|c|c|c|c|}
\hline Sample & D Shore hardness & $\begin{array}{c}\text { Impact strength } \\
\left(\mathbf{k J} \cdot \mathbf{m}^{-2}\right)\end{array}$ & VST $\left({ }^{\mathbf{}} \mathbf{C}\right)$ \\
\hline PLA & & $16.1 \pm 6.1$ & $56.0 \pm 1.0$ & $53.9 \pm 0.7$ \\
\hline PLA/ASF & $78.0 \pm 1.2$ & $6.2 \pm 1.1$ & $77.0 \pm 1.2$ & $64.0 \pm 1.2$ \\
\hline PLA/ASF + ESAO & $83.8 \pm 1.3$ & $9.3 \pm 1.5$ & $81.9 \pm 1.6$ & $67.4 \pm 0.8$ \\
\hline PLA/ASF + AC & $83.8 \pm 1.8$ & $8.5 \pm 1.6$ & $81.8 \pm 1.2$ & $67.7 \pm 1.2$ \\
\hline PLA/ASF + MLO & $83.0 \pm 1.6$ & $10.1 \pm 1.9$ & $79.6 \pm 1.3$ & $66.9 \pm 1.7$ \\
\hline
\end{tabular}


Figure 1
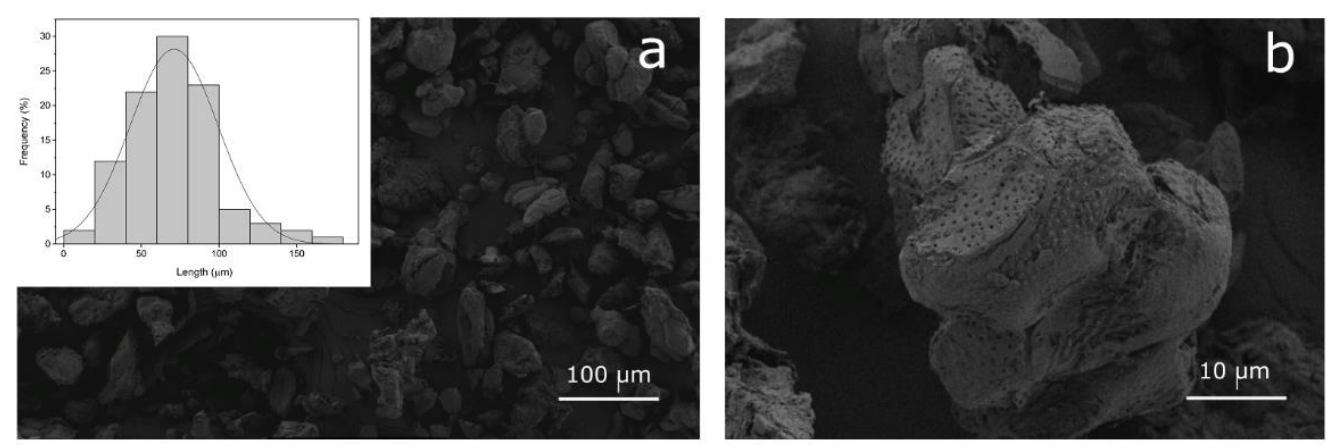
Figure 2

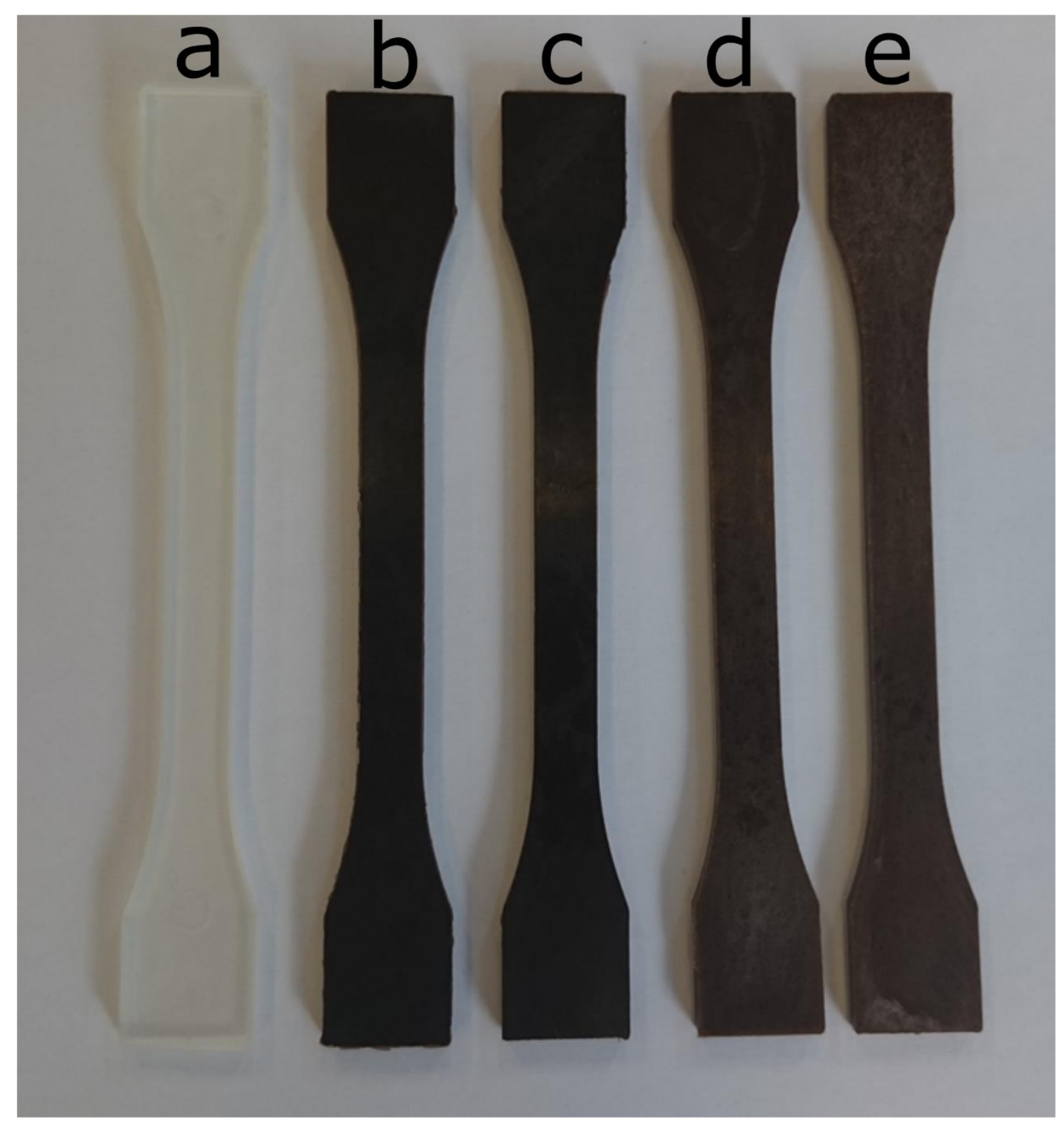


Figure 3

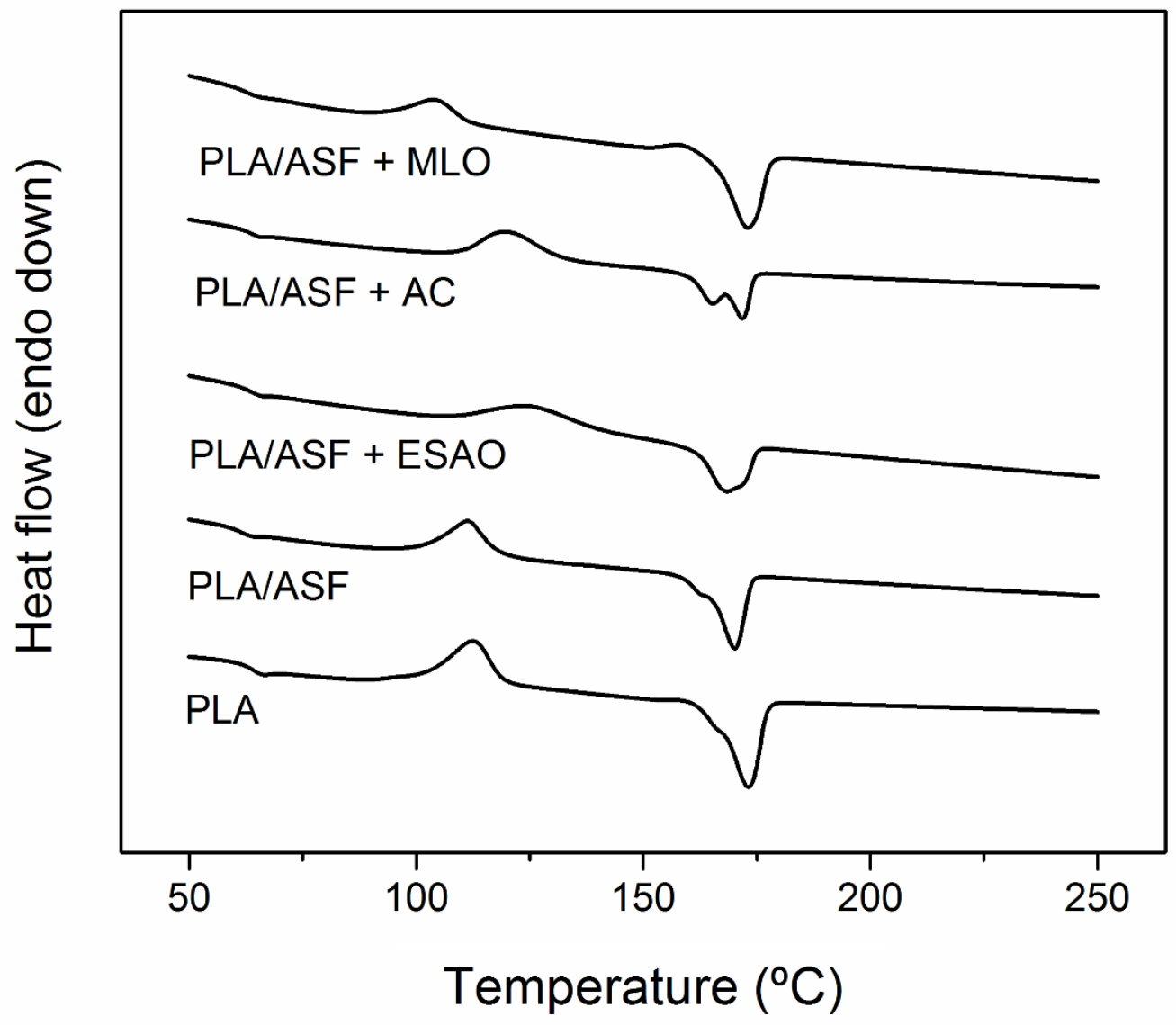




\section{Figure 4}
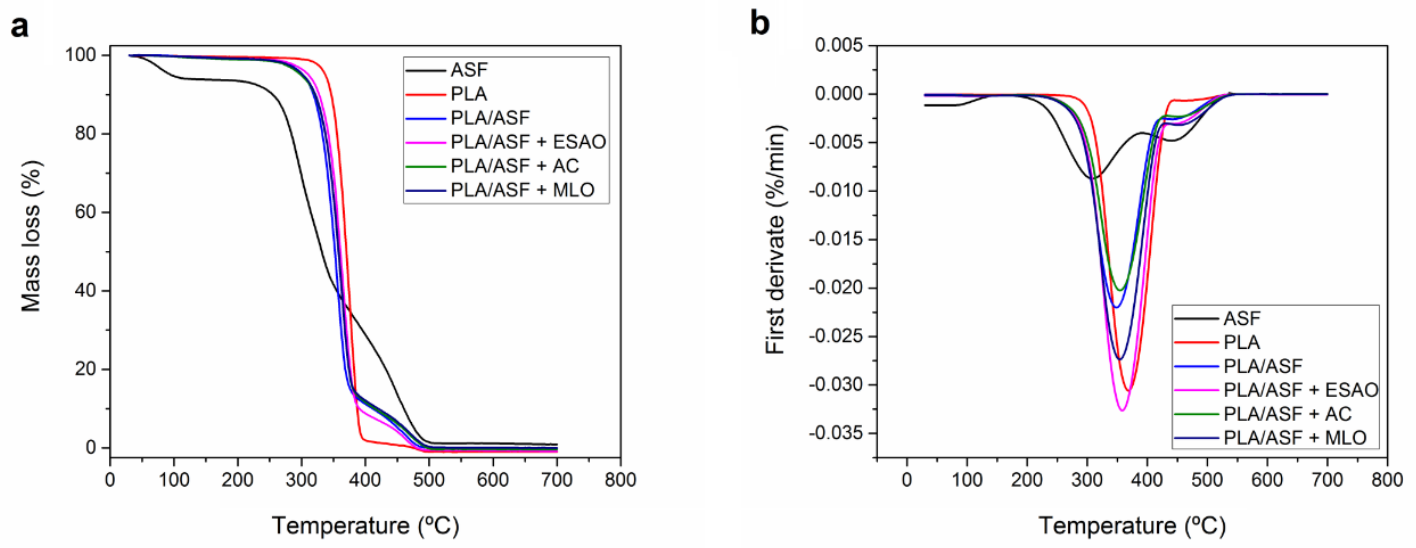


\section{Figure 5}
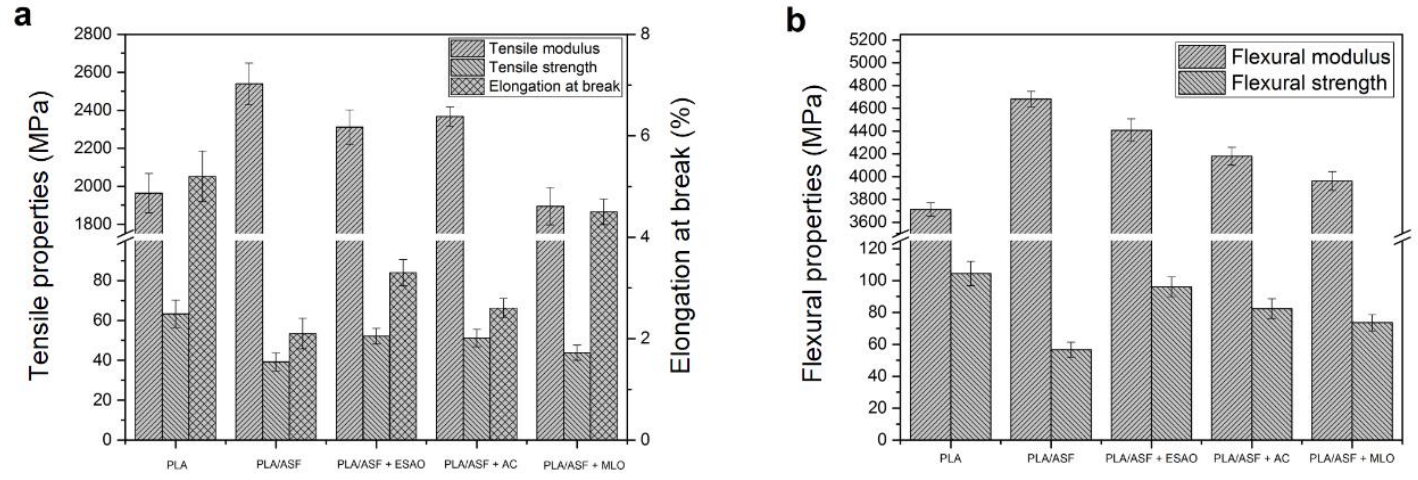


\section{Figure 6}
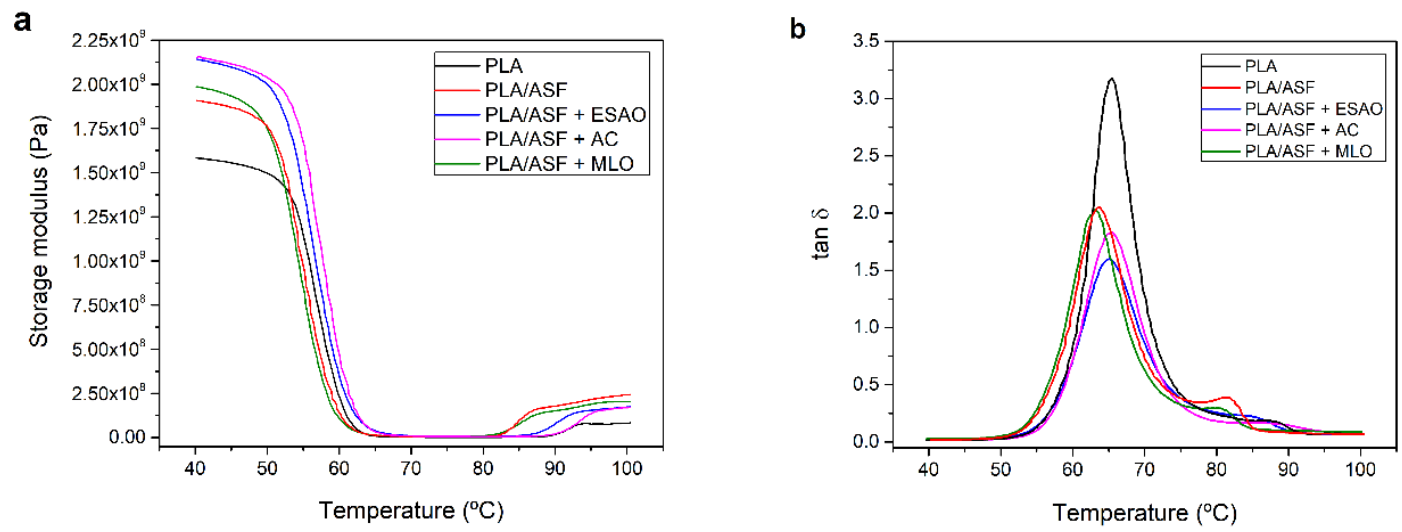
Figure 7
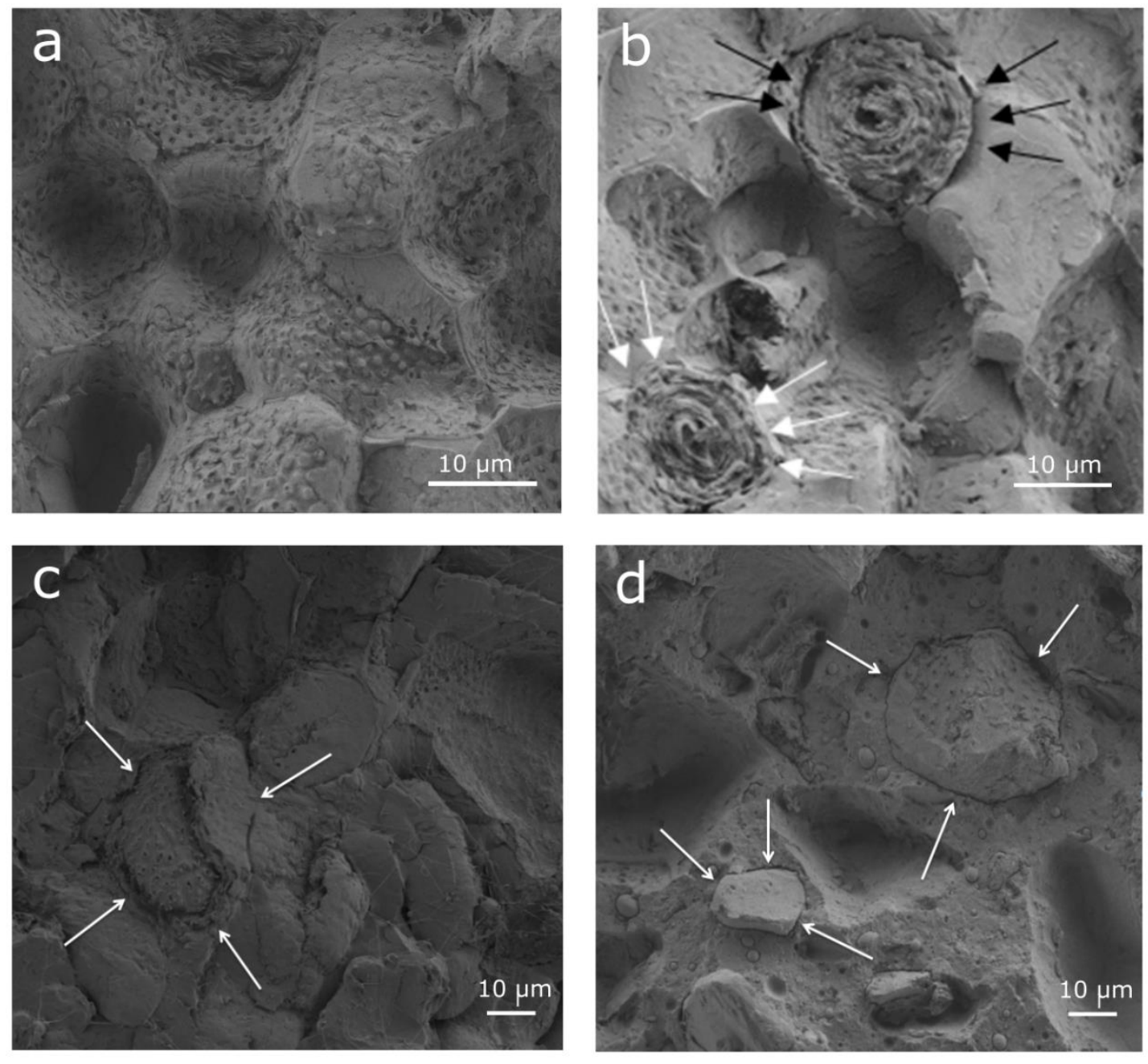
Figure 8

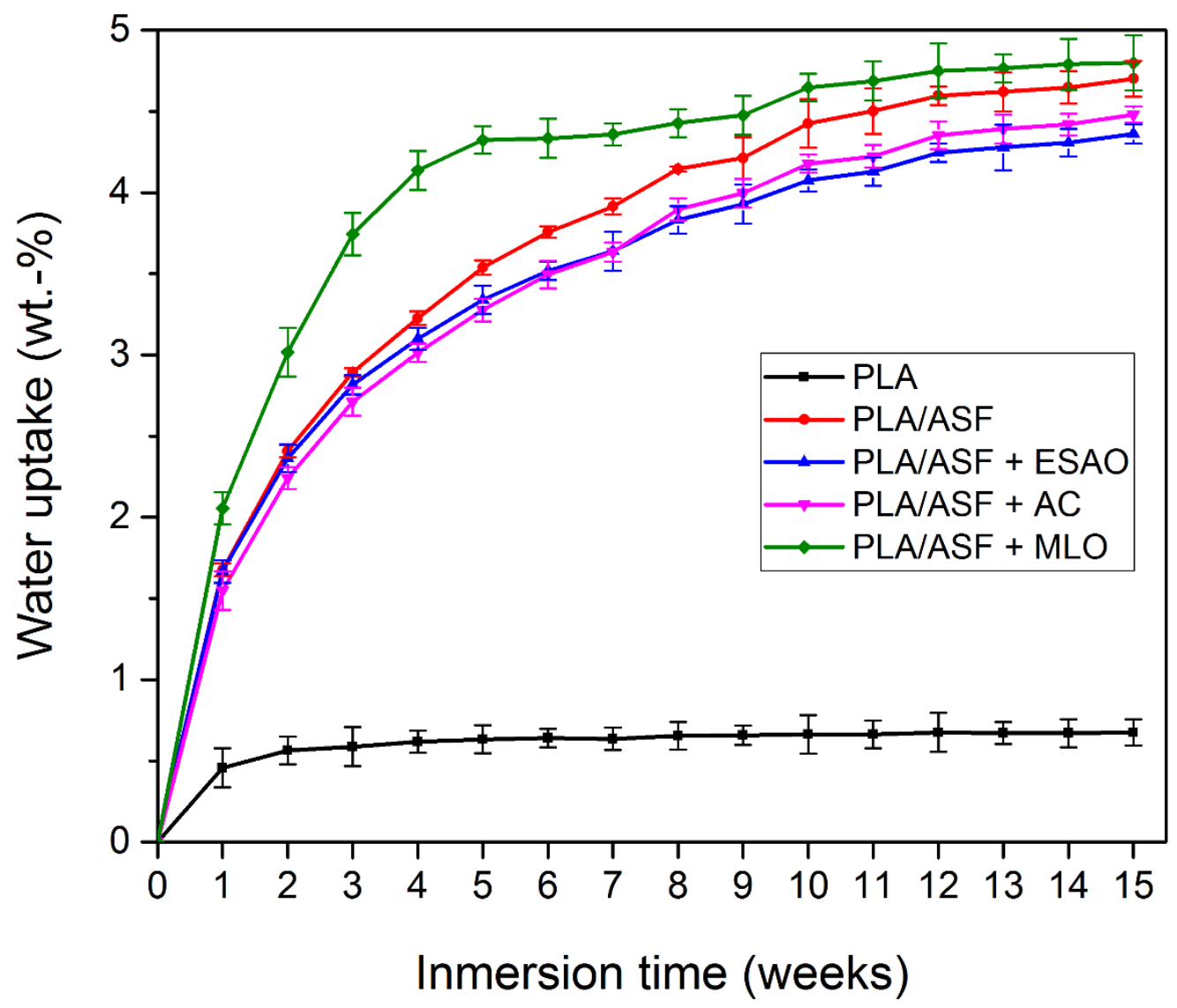

